\title{
O cinema como construtor do ser: um ensaio sobre o discurso cinematográfico de $O$ Fantasma, de João Pedro Rodrigues
}

Cinema as a builder of being: an essay on the cinematographic discourse of O Fantasma, by João Pedro Rodrigues

Sara Pereira Porto - Universidade Autónoma de Lisboa spporto@hotmail.com

https://doi.org/10.26619/978-989-9002-14-2.10

\begin{tabular}{|c|c||c|}
\hline Recebido / Received & Aceite / Accepted & Publicado / Published \\
25.06 .2020 & 17.07 .2020 & 15.01 .2021 \\
\hline
\end{tabular}

Como citar este capítulo / How to quote this chapter:

Porto, S. P. (2021). "O cinema como construtor do ser: um ensaio sobre 0 discurso cinematográfico de $O$ Fantasma, de João Pedro Rodrigues". In Lourenço, J. \& Lopes, P. (eds.), Comunicação, Cultura e Jornalismo Cultural. Lisboa: NIP-C@M \& UAL, (pp. 215-236), disponível em https://repositorio.ual.pt/handle/11144/4758 DOI https://doi. org/10.26619/978-989-9002-14-2.10 


\section{Resumo}

Sentamo-nos para observar. Esperamos que o que observamos nos faça sentir. Revemo-nos, muitas vezes, naquilo que enxergamos e entregamo-nos a representações que nos são impingidas nas telas. O mundo dos media encontra-se contaminado por jogos de interesses, de poder e de capitalismo. Damos por nós a interrogarmo-nos sobre o que somos. A dúvida provém muitas vezes da esponja em que nos transformamos à medida que evoluímos. Precisamos sempre de auxílio. Esperamos constantemente por imagens, mesmo não sabendo desconstruílas. O cinema, o grande universo da criatividade, imaginação, liberdade e poesia. Em que medida não se encontra também ele afectado? Existirá nele uma missão intrínseca de cada vez que se faz nascer um filme? É indubitável reconhecer a existência da criação de estereótipos no discurso cinematográfico de género, mas é importante compreender a sua função crítica e social: por tirar a capa a várias realidades, por nos oferecer uma panóplia de caminhos, por nos confrontar e nos obrigar a reflectir. Ao ver um filme somos, quase sempre, invadidos por emoções, sentimentos e espíritos que são capazes de nos assombrar por diversos dias. Essa é a magia da cinematografia e João Pedro Rodrigues é uma prova disso. Abrindo-nos a porta para o seu cosmo, convida-nos a abraçar os seus desvaneios nos quais nos perdemos para depois nos encontrarmos. O Fantasma traz à tona a forma mais crua da sexualidade, fetichismo e perversão. De que forma incorre no erro de representar uma minoria? Gostará João Pedro Rodrigues de arriscar? A resposta é sim. E agora? Como o desconstruir? 


\section{Abstract}

We sit down to watch. We hope that what we observe will make us feel. We often review what we see and give ourselves to representations that are imposed on us by the canvases. The world of media is contaminated by games of interests, power and capitalism. We find ourselves wondering what we are. Doubt often comes from the sponge we transform ourselves into as we evolve. We always need help. We constantly wait for images, even though we do not know how to deconstruct them. Cinema, the great universe of creativity, imagination, freedom and poetry. To what extent is he not affected too?

Is there an intrinsic mission in it every time a movie is born? It is undoubtedly to recognize the existence of stereotypes in gender film discourse, but it is important to understand its critical and social function: by taking the cover to various realities, for offering us a panoply of paths, for confronting us and forcing us to reflect. When watching a movie we are almost always overwhelmed by emotions, feelings and spirits that are able to haunt us for several days. This is the magic of cinematography and João Pedro Rodrigues is proof of this. By opening the door to your cosmos, it invites us to embrace its fads in which we are lost and then meet. The Phantom brings out the crudest form of sexuality, fetishism and perversion. How do you incur the mistake of representing a minority? Will João Pedro Rodrigues like to take a chance? The answer is yes. What's next? How to deconstruct it? 


\section{O cinema como arma de libertação}

Podemos, muito facilmente, associar o cinema à liberdade e a liberdade à arte. Quase que parecem termos que andam de mãos dadas e que não sobreviveriam à separação. Neste capítulo, tentaremos analisar a dita mudança de paradigma e o acordar para uma nova forma de ver e fazer cinema em Portugal. Para isso, recuemos uma década no século que deu luz a novos cineastas.

Segundo Daniel Ribas (2017), esta descoberta abriu portas a várias alterações nos modos de produção e nas escolhas cinematográficas, nomeadamente a nível de temáticas. Mas, para que tal fosse possível, é importante fazermos a viagem até à década, responsável por todas essas mudanças. A adesão de Portugal à então Comunidade Económica Europeia pautou uma profunda evolução cultural no país, um novo contexto político e económico fez-se sentir e os auxílios financeiros e criativos começaram a surgir. Esta adesão resultou em fundos que concederam e fortificaram relações entre o poder político e as políticas culturais. O cinema começou a ser visto como algo estruturante para a democracia. A instituição de um Ministério da Cultura em 1995 é prova disso mesmo, responsável pelo aumento e alargamento dos apoios concebidos à Sétima Arte.

Um dos resultados mais marcantes desta evolução (consequente com as diversas formas de financiamento que o cinema sofreu), foi o surgimento de uma nova geração de cineastas, com um olhar novo e uma vontade de desconstruir, desmistificar e arriscar. No seu seio encontrava-se João Pedro Rodrigues, que 
será objeto de estudo neste texto. Tal como muitos outros (Marco Martins, Catarina Ruivo, Raquel Freire, Jorge Cramez, Tiago Guedes/Frederico Serra, Miguel Gomes ou Sandro Aguilar), no início deste século, este beneficiou do apoio às primeiras obras, a curtas e a longas-metragens. Foi este o impulso à sua montra artística, o que Ihe permitiu dar-se a conhecer, tanto nacional como internacionalmente. $\mathrm{O}$ boom da diversidade de abordagens temáticas, de narrativas, cinematográficas e intelectuais.

A verdade é que todos esses jovens cineastas representam uma tradição de cinema de autor, espelhando a sua visão do mundo, das formas, do ser humano, da liberdade e subjetividade. Começa-se a dar mais importância ao visual estético e à importância da reinvenção de narrativas.

Temas pouco explorados foram trazidos à tela e o indivíduo, a identidade e o género assumem um papel fulcral nesta reinvenção das películas.

\footnotetext{
"Uma aposta discursiva pela exposição da busca de identidade e pela experimentação vital do indivíduo entendido como uma unidade, mas também como poder e resistência. A transgressão sexual ou genérica, a reinvenção social e cultural passarão a fazer parte do núcleo do imaginário do cinema português." (Valdellós, 2016).
}

\section{O cinema queer}

João Pedro Rodrigues é considerado um dos arquitetos desse novo olhar sobre o cinema. Distinto pelo modo como ofereceu 
ao cinema português o cinema queer, arriscou e deu protagonismo aos ambientes mais marginais do mundo travesti e das relações homossexuais.

\begin{abstract}
"Rodrigues prossegue na senda de fazer cinema de risco total, que não se confunde com o de mais ninguém: original, só, no desequilibrado balanceado de quem conhece os mestres e resiste à cinefilia fácil, "encerrado» numa visão totalizante de pura matéria fílmica." (Torres, 2009).
\end{abstract}

Segundo Caterina Cucinotta (2013),

“a teoria queer é uma teoria crítica sobre sexo e género que surge no início dos anos 90 do século passado no seio dos estudos gays, lésbicos e da teoria feminista. Seguindo as teses de Michel Foucault, Jacques Derrida e Julia Kristeva, esta teoria discute a naturalidade da identidade de género, da identidade sexual e dos atos sexuais de cada indivíduo e afirma que estas são, por inteiro ou em parte, construídas socialmente, pelo que os indivíduos não podem ser realmente descritos pela mera utilização de termos gerais como "heterossexual» ou "homossexual», «mulher» ou «homem»."

A teoria queer empenha-se em desmistificar o que é tido como "normativo" ou "desviante", daí a sua recusa na "criação de categorias entidade/grupo, artificiais e socialmente atribuídas, baseadas na divisão entre os que compartilham um uso, um hábito ou um estilo de vida e os que não o compartilham" (Cucinotta, 2013). 
No cinema queer, o foco é a sexualidade. Através dela, o realizador tenta mostrar as coisas tal como são, de uma forma crua e transparente, sem que o espectador possa ser induzido a juízos. Contudo, tratando-se de cinema e não da realidade, é possível que exista sempre um ponto de vista predominante, pelo que a forma como os factos são retratados e gravados acabará por conter juízos que penderão para cada lado da balança.

\section{As representações socias na tela}

De acordo com Rosa Cabecinhas (2009), as representações sociais são sinónimo de uma modalidade de conhecimento que é construída e partilhada. Essa modalidade acaba por resultar numa perceção de realidade comum a um determinado grupo. A perceção de realidade de que fala corrobora com a ideia de Denise Jodelet (1989) de que essas representações concebem a maneira como os indivíduos se apoderam do mundo e criam matrizes de comportamento.

O conhecimento é também uma das palavras-chave deste conceito, pois as representações sociais influenciam processos de disseminação e assimilação de conhecimento. Através desse conhecimento é possível construir identidades tanto individuais como sociais (Cabecinhas, 2009), e esse pode ser um veículo de apropriação de preconceitos e estereótipos, de comportamentos e visões, face a determinados grupos. Por essa razão, as representações sociais podem ser consideradas tanto um instrumento de introspeção e mudança psicológica da nossa reali- 
dade, como um resultado de apropriação da realidade que nos é exterior e distante, e que nos faz ter um determinado comportamento face a situações, pessoas e grupos.

Segundo Dina Maria Martins Ferreira e Tibério Caminha (2016), "algumas formas de construção do discurso cinematográfico são indissociáveis de políticas representacionais específicas de género, que, por sua vez, têm por objectivo a legitimação de posições na hierarquia social". Por isso, é importante, para além de considerar a cultura como um forte instrumento de entretenimento, procurar provar que é possível entendê-la em contextos de luta de interesses de comunidades estigmatizadas.

O discurso cinematográfico pode e deve ser um fenómeno simbólico capaz de generalizar e naturalizar visões de mundo particulares, não só neutralizando possíveis diferenças como também causando efeitos na reprodução das relações sociais. Isto é, ver para além do preconceito, neutralizar possíveis diferenças. Através do que visionamos, talvez possa ser possível embarcar numa reflexão, num processo de aceitação do outro, da diferença.

"Tal cultura poderia desempenhar um papel de dupla função: não só manifestações de identidades homossexuais não serviriam apenas para reforçar a existência de um grupo social considerado minoria - como ponto de identificação e/ou autoidentificação do Eu subjetivo com a homossociabilidade objetiva -, mas, também, reconsiderações do Outro - heterossexual ou simpatizante - em relação a estilos, e práxis social dos LGBTs, 
reconsiderações que, potencialmente, nulificariam a homofobia por meio da negociação de saberes" (Ferreira e Caminha, 2016).

Olhando de novo para o discurso cinematográfico queer e considerando-o um discurso de oposição à heteronormatividade, este rompe com a natureza da indústria comercial cinematográfica, considerada sexista e pouco tolerante, onde não existe lugar para a diferença, já que as suas narrativas substanciam os papéis sociais de género heteronormativos. Neste ponto, entra a interrogação sobre o papel que a cultura tem vindo a desempenhar para a desconstrução de padrões. A cultura é, também, uma das criadoras de estereótipos, pois as ditas "minorias" são, muitas vezes, representadas de forma satírica, onde impera o lugar comum, a imitação barata e cómica das suas diferenças - "o que relega a lésbica, o gay, o bissexual, o travesti e o transgénero ao plano do subalterno" (Spivak, 2010).

É, pois, reconhecido ao discurso cinematográfico de género uma função crítico-social, por "pôr o cliché em evidência para discussão", revelando que as minorias não têm controle sobre a sua própria representação e "enfatizando uma luta política e teórica contra a repetição de imagens negativas em favor da necessidade de imagens positivas" (Lopes, 2006).

Deparamo-nos, então, com o sentido e o contrassentido na representação imagética, que acabam por possibilitar a persuasão e a dissuasão das massas e a fragmentação do sentido apassivador e alienador pelas massas (Baudrillard, 1991). 


\section{João Pedro Rodrigues: o cineasta}

Nascido em Lisboa, em 1966, João Pedro Rodrigues, realizador português, começou a sua vida académica na Universidade de Lisboa, em Biologia. Contudo, o desejo de ser ornitólogo depressa foi substituído pela paixão pelo cinema, tendo estudado na Escola Superior de Teatro e Cinema.

Com uma visão bastante peculiar, a sua carreira internacional iniciou-se em 1997, com a curta-metragem Parabéns! que Ihe valeu o Leão de Prata no 54ㅇ Festival Internacional de Cinema de Veneza. Mas foi três anos mais tarde que se estreou nas longas-metragens, com a primeira, O Fantasma, estreada em competição no 570 Festival Internacional de Cinema de Veneza.

São obras que exploram os tabus, o género, o animalesco e o desejo humano. João Pedro Rodrigues conjuga vários géneros cinematográficos, tais como o cinema clássico, o documental e o experimental. Conjunção que reflete, de alguma forma, a história do cinema.

Conta já com 17 trabalhos realizados que abraçam o reconhecimento internacional pela sua irreverência e verdade. Desse leque, as longas-metragens que se destacaram foram Odete, em 2005, a segunda longa-metragem que venceu vários prémios, entre eles uma Menção Especial "Cinémas de Recherche" na 37ạ Quinzena dos Realizadores do Festival de Cannes. Em 2009, 
realizou Morrer como Um Homem, que teve estreia mundial no 40 Un Certain Regard, no Festival de Cannes e, mais tarde, em 2007, o projecto fora seleccionado pela Cinéfondation para o Atelier do Festival de Cinema de Cannes, quando, simultaneamente, a curta-metragem China, correalizada com João Rui Guerra da Mata, foi apresentada na 39ạ Quinzena de Realizadores. Mais recentemente, João Pedro Rodrigues voltou a ser aclamado pela sua mais recente obra O Ornitólogo, ganhando o Leopardo de Prata de Melhor Realizador no 69으 Festival Internacional de Cinema de Locarno, em 2016.

Numa conversa num jardim em Sintra, João Pedro Rodrigues confidenciou a Antoine Barraud que não sonha, que nunca se lembra dos sonhos. Que todos os seus filmes começam com uma imagem e que é a partir dessa que se constrói a história. Que gosta de ir contra as coisas que já viu. Que gosta de filmes de "nuit". Que vê as cenas de sexo dos seus filmes como se fossem cenas de conversa, que lhes dá a mesma importância. Que não gosta da obsessão pelo naturalismo, que a realidade é que decide como os corpos estão e são. Que gosta de dar a oportunidade aos não atores, ao real.

Uma forma tão diferente de ver e viver o cinema. Este é João Pedro Rodrigues que se considera tímido e não gosta de conversar sobre os seus filmes, pois vive-os no momento e, quando terminam, não gosta de lá voltar. 
Segundo Nathan Lee (2006), a arte de Rodrigues é comparada a uma fusão de consciência e representação que nos faz acordar. Um cinema desconcertante que vive de autobiografias disfarçadas.

\section{O Fantasma: "Ninguém pode viver sem amor"}

O Fantasma estreou-se em 2000 e teve a sua internacionalização enquanto participante na competição oficial do Festival Internacional de Cinema de Veneza, no mesmo ano. Venceu o prémio de Melhor Filme no Festival de Cinema Lésbico e Gay de Nova Iorque e no Festival Internacional de Cinema de Belfort. Foi um dos primeiros filmes portugueses a ser lançado comercialmente em Nova lorque e o seu protagonista, Ricardo Meneses, foi nomeado para o Globo de Ouro da SIC como melhor actor num papel principal em 2001.

O filme tornou-se imediatamente objeto de análise ao ser o primeiro filme português, de sempre, a abordar direta e cruamente um tema homossexual.

"Uma noite os seus olhos encontraram o fantasma dos seus sonhos e acorda na obsessão do amor. Enfeitiçado, espia-o. Remexe-Ihe no lixo. Segue-o. Invade-Ihe a casa. Urina-Ihe a cama, marcando território como um cão. Agora não comanda o jogo mas avança, mesmo sabendo que só pode perder. 0 cerco fecha-se. E as mãos que queriam acarinhar ficam algemadas, viciadas na rejeição. Só lhe resta a vingança. A máscara do desejo, o fato de borracha negra, transforma-se na sua última mo- 
rada. Refugia-se no caos, nos restos que o mundo já não quer. Está sozinho. Já não é deste mundo." (Sinopse da contracapa do DVD).

Imaginemo-nos perseguidos pelas nossas fomes sexuais e fetiches. É dessa forma que vive Sérgio, personagem principal desta obra fílmica, que se vê obrigado a construir o seu próprio mundo, vivendo numa frenética busca pela satisfação do desejo. $\mathrm{O}$ jovem passa os dias entre o seu pequeno e pouco cómodo quarto de pensão, encontros sexuais com outros homens e o trabalho nocturno de recolha de lixo na zona norte de Lisboa. Da sua vida fazem parte muito poucas caras, companhias, daí a carência demonstrada pelo personagem ao longo do filme. Existe um cão, Lorde, que serve de guarda no depósito de lixo e com o qual mantém uma ligação de espelho, já que muitos dos seus comportamentos se assemelham aos do animal. Fátima, uma colega de trabalho com a qual vive um jogo de sedução/desprezo/violência traz à tona o lado mais desprezível do jovem que a olha como objecto. Existe também um polícia que o vigia e com o qual acaba por ter uma ligação sexual, um homem que aparece e desaparece, e que se satisfaz sexualmente em pequenos becos das ruelas lisboetas, e o rapaz da mota pelo qual Sérgio acaba por nutrir ambíguos sentimentos. É aí que o seu lado obcecado surge, com a confusão entre obsessão e amor.

A recolha dos objetos pessoais, o rondar da casa, a invasão da privacidade, a perseguição, a perversão dos comportamentos empurra-nos até uma espiral alucinogénica onde Sérgio se perde, se transforma e se alimenta, acabando por materializar o 
fantasma de seus sonhos. Mas a rejeição fá-lo sentir-se mais sozinho que a própria solidão e acaba por se refugiar no caos, nos restos do mundo ao qual não mais pertence.

"Trata-se de uma ficção sobre a brutalidade do desejo e a impotência frente à rejeição. Queria retomar os gestos íntimos da solidão de um corpo frente à impossibilidade do amor dividido" (Rodrigues, 2019).

\section{Recortes de um filme}

A primeira imagem é a de um cão a correr num corredor estreito e escuro. Tal como refere nas suas entrevistas, João Pedro Rodrigues (2000) parte de imagens e deixa que estas iniciem o seu processo criativo. A escuridão do corredor faz-nos entrar num quarto onde decorre um ato sexual entre dois homens. Somos imediatamente confrontados com a crueza da acção. Um bom cartão de "boas-vindas" para que seja possível perceber a viagem que nos propõe.

A pele de um deles encontra-se escondida por baixo de um fato preto de látex que só revela os olhos e a boca. $\mathrm{O}$ outro, completamente nu, transmite a ideia de um objeto submisso que se encontra a ser dominado. $O$ detalhe, os gestos, a atenção sobre os corpos... $\mathrm{O}$ espectador tem acesso aos mais pequenos fragmentos de pele, de tecidos, de formas. O erotismo e a perversão.

Na terceira cena do filme, um camião do lixo apresenta-nos aquele que será o nosso protagonista: Sérgio. Trabalhador da 
noite lisboeta, recolhe lixo dos bairros e casas da capital. Paira a dúvida. Quem é o homem no fato de látex? Será Sérgio? Serão eles a mesma pessoa? Será apenas um sonho?

"O Fantasma é, como o título sugere, feito de coisas intangíveis, figuras fantasmagóricas que atravessam lugares fantasmagóricos. Rodrigues, disparado em condições de baixa luminosidade e em torno do seu bairro, transforma o residencial de Lisboa numa paisagem crepuscular de estranheza radical (...) A ambição penetrante de Rodrigues de explorar bloqueios misturando-os com conjuntos cinematográficos tão singulares evoca as formas e trajectórias da própria luxúria. Tudo faz dele o mais novo bicha do bloco, mas isso não significa que não te devas masturbar para o cinema dele" (Lee, 2016).

Segundo a autora, Sérgio (o personagem principal) encarna "o espírito da porta que conduz para fora, a encruzilhada, a estrada ao anoitecer. A única que corre a partir de uma realidade para outra não pertencendo a nenhuma delas" (Lee, 2016).

Rodrigues admite, em várias entrevistas, que as suas obras cinematográficas acabam por pertencer ao género de aventura e $O$ Fantasma corrobora essas afirmações, já que Sérgio se comporta como um verdadeiro super-herói: tendo uma vida quotidiana, um emprego e um quarto, vive, também, uma real alucinação quando entra no mundo do fetichismo. Passando os dias a saltar portões, a entrar e sair de quartos, é visível a sua inquietação sexual e algumas frustrações que o conduzem a comportamentos animalescos. As lambidelas dadas na cara de Fátima, o rasgar 
dos sacos do lixo com os dentes, a masturbação no duche tendo o cabo enrolado ao pescoço ou o utilizar das luvas, o farejar das cuecas tiradas ao rapaz da mota, o urinar em cima da cama deste...

É importante analisar também a tipologia dos cenários no filme. Nenhum deles nos chega a ser familiar, mantendo-se no anonimato. Sabemos que estamos em quartos de outros, em portões, em carros, em aterros, em parques de estacionamento, mas nunca nenhum destes locais fica o tempo suficiente no ecrã para que o possamos conhecer e identificar. Não conhecemos as entradas, as portas de saída. Segundo Ana María Sedeño Valdellós (2016), "os lugares são tão solitários como o próprio protagonista: estão reduzidos à sua essencialidade".

Mas, afinal quem é Sérgio? O que representa este personagem tão desconcertante?

\section{Os conceitos de "corpo natural" e "corpo revestido"}

Contemporaneamente, assistimos a um crescimento de um leque de novas teorias que acabam por desenvolver a relação entre o revestimento do corpo como um travestismo, ao mesmo tempo que permitem a não adesão a estereótipos sociais e sexuais, associados a performances que provocam prazer e reflexão (Cucinotta 2013).

"O travestismo do género sexual produz, em particular, resultados diferentes em função do seu contexto, deixando aflorar 
significados e metáforas interessantes, tanto pela ideia do género sexual como pela ideia da indumentária" (Cucinotta 2013).

A autora dá sustentação a conceitos que, no filme, se relacionam e permitem compreender as duas personas que vivem dentro de Sérgio: o conceito de "corpo natural" e o do "corpo revestido". O corpo natural serve de armadura para tudo aquilo que se encontra escondido no seu mundo "proibido", no seu mundo fantasiado. Esse "corpo natural" é utilizado para manter uma posição socialmente "normalizada" que lhe permite arranjar formas de contacto com o mundo onde vive, mesmo sem saber viver, mesmo sem se encaixar. Ao mesmo tempo que lhe possibilita, sobriamente, vestido com o seu fato de homem do lixo, recolher o necessário para satisfazer, mais tarde, instintos escondidos.

Já o "corpo revestido" é aquilo que Sérgio quer esconder e pode ser ampliado a todas as castrações que o ser humano impõe a si próprio. $\mathrm{O}$ fato de látex, as luvas, as cuecas... Esse "corpo revestido" acaba por atenuar todos os comportamentos tomados pelo fantasma já que, na utilização de cada objeto, o jovem pode sentir-se culpado apenas pela metade, afastando-se do "corpo natural". Precisamos de criar conceitos e arranjar formas de fugir aos nossos devaneios.

No momento da rejeição, quando Sérgio é confrontado por João (o rapaz da mota), podemos compreender que não se trata apenas de uma rejeição amorosa, mas sim social. Sérgio é destruído pela sede de vingança e consumido pelo fato de látex. Se, no iní- 
cio do filme, este vagueia em aterros (os locais preferidos do seu fantasma), vestido com o seu uniforme do lixo e tendo por objectivo mais tarde satisfazer os desejos desse fantasma, no final do filme os papéis invertem-se. Sérgio desaparece, deixando que o fantasma se apodere do seu corpo, dos seus comportamentos. Vagueia no meio da lixeira e procura restos da humanidade, os restos que os outros desprezam. $\mathrm{O}$ seu corpo transforma-se e a sua personalidade é alterada.

\section{A representação social/reflectiva de uma "minoria sexual"}

Parece-nos óbvia a frustração do personagem que se vê e sente como diferente. Em todo o filme, são-nos mostradas as suas estratégias de viver num mundo ao qual sente não pertencer. Sérgio é um jovem homossexual, trabalha como recolhedor de lixo, mora num pequeno quarto numa pensão, a sua única companhia é um cão, tem comportamentos animalescos e não controla a sua sede pela obtenção de prazer através da realização dos seus fetiches.

Em que medida $O$ Fantasma não é uma alavanca para a criação de estereótipos e a estigmatização de um grupo? Ou será, por outro lado, um alerta quase metafórico e exagerado para a situação em que vivem as pessoas que integram estes grupos marginalizados?

Estamos em crer que ainda vivemos ancorados em valores conservadores mas, aos poucos, vemos com esperança o caminho 
de aceitação do outro e a filmografia de João Pedro Rodrigues contribui para essa evolução. Não podemos considerar que o filme não possa ser mal interpretado, que a partir dele algumas pessoas não possam considerar que "todos os homossexuais são assim". Contudo, é impossível controlar cada interpretação. O ponto que consideramos fulcral é a singularidade e crueza deste tipo de cinema que, sem qualquer tipo de tabu, nos coloca questões mesmo sem o fazer. $O$ importante é que daí derive uma reflexão, uma discussão. Que consigamos ir além das imagens que nos são transmitidas.

E, afinal, quem somos nós? O ser humano é um "bicho" carregado de perversões, apenas não estamos habituados a ver-nos na tela. O Fantasma apresenta-nos um personagem carregado de uma complexidade que transpira angústias, frustrações e perversões. Por essa razão, é muito fácil que haja a criação de uma relação de empatia quase que inconsciente.

“É uma ficção muito concreta. Acho que muitas pessoas ao verem o filme poderão encontrar coisas em comum com a vida delas, porque eu se calhar também encontro algumas coisas em comum com a minha vida... eu não escrevi o filme sozinho, e ao escrever o filme com outras pessoas também foi isso de procurar outras experiências, para tornar o filme mais rico" (Rodrigues, 2000).

Amante do cinema autêntico, João Pedro Rodrigues, em O Fantasma, fez questão que nenhuma das personagens do filme fosse efetivamente um ator (profissional). Admite ter feito uma 
procura exaustiva de pessoas com o perfil ideal para aquilo que ambicionava e essa sua característica enfatiza a vontade de revolucionar a maneira de se fazer cinema. Todos poderíamos ser o personagem principal.

É através dessa maneira empática que qualquer representação mal interpretada pode ser desconstruída. O importante é observar para além do óbvio. É possuir a pré- disposição de sentir. De compreender o outro. Não cair em ideias generalizadas e em ideias pré-concebidas.

Talvez possamos pensar O Fantasma como uma espécie de grito de ajuda. E, agora, na primeira pessoa, não me parece assim tão difícil abraçarmos a tolerância.

\section{Bibliografia}

Agência - Portuguese Short Film Agency (s.d.) João Pedro Rodrigues. Disponível em: https://agencia.curtas.pt/realizadores/show/529

Associação Portuguesa de Realizadores (s.d.) João Pedro Rodrigues. Disponível em: https://aprealizadores.com/realizadores/joao-pedrorodrigues/

Barraud, A. (2016). Le Jardin de Fauves. França: Post-Éditions.

Baudrillard, J. (1991). La Transferência del Mal Ensayo sobre los Fenômenos Externos. Barcelona: Anagrama.

Cabecinhas, R. (2009). “Investigar representações sociais: metodologias e níveis de análise”. In Baptista, M. M. (ed.) Cultura: Metodologias e Investigação. Lisboa: Ver o Verso Edições, pp.51-66. 
Cucinotta, C. (2013). "Origens possíveis e consequentes desenvolvimentos contemporâneos da longa-metragem O Fantasma, de João Pedro Rodrigues". In Pereira, A. C. \& Cardoso e Cunha, T. (ed.) Geração Invisível: Os Novos Cineastas Portugueses. Covilhã: LabCom, pp. 105-128.

Ferreira, D. \& Caminha, T. (2018). "Vozes da diversidade: Gênero queer em discurso cinematográfico". Revista Discursos Contemporâneos em Estudo 3(1), pp. 7-24.

Galvão-Viana, L. \& Carvalho, I. (2014). "Gêneros inteligíveis em cena: o cinema e a produção de verdades sobre os corpos". Athenea Digital 14(2), pp. 171-193.

Jodelet, Denise (1989). "Representações Sociais: um domínio em expansão". In D. Jodelet (ed.) Les représentations sociales. Paris: PUF, 1989, pp. 31-61.

Lee, N. (2006). Mysterious Skin: João Pedro Rodrigues Cinema of Carnal Transcendence, Film Comment. Nova Iorque: Lincoln Center.

Lopes, D. (2006). "Cinema e género". In Fernando Mascarello (ed.) História do Cinema Mundial. Campinas: Papirus Editora. pp. 376-394.

O Fantasma. (2000). [DVD] Directed by J. Pedro Rodrigues. Lisboa: Amândio Coroado.

Rodrigues, J. P. (2000). "João Pedro Rodrigues - O Fantasma". PortugalGay.pt (A. Serzedelo, Entrevistador), disponível em: https:// portugalgay.pt/entrevista/ioao pedro rodrigues.asp?0

Rodrigues, J. P. (2019). O Fantasma. In 43a Mostra Internacional de Cinema de São Paulo, disponível em: http://43.mostra.org/br/ filme/4938-O-Fantasma

Ribas, D. (2017). "Os últimos autores do cinema português", A Cuarta Parede, (1), disponível em: http://www.acuartaparede.com/ultimocinema-portugues/.

Spivak, G. C. (2010). Pode o subalterno falar?. Belo Horizonte: Editora UFMG. 
Torres, M. J. (2009). "Tempo para amar, tempo para morrer", Público, disponível em: https://www.publico.pt/2009/10/14/culturaipsilon/ critica/tempo-para-amar-tempo-para-morrer-1655635

Valdellós, A. (2016). "Imaginarios del cuerpo y la memoria en el cine português contemporáneo: reflexiones sobre el cine de Miguel Gomes y João Pedro Rodrigues", Universidad de Málaga, disponível em: https://dialnet.unirioja.es/descarga/articulo/5716296.pdf 